\title{
The Public Sphere and the Norms of Transactional Argument
}

\author{
JEAN GOODWIN
}

\begin{abstract}
An outsider to argument theory, should she look through the rich outpouring of our recent work, might be amused to find us theorists not following our own prescriptions. We propound our ideas, but we don't always interact with each otherwe don't argue. The essays by William Rehg and Robert Asen make promising start on rectifying this difficulty. I want to discuss them, first, to show how they acknowledge in exemplary fashion a pair of challenges I think we should all be addressing; and next to consider their specific responses.
\end{abstract}

\begin{abstract}
Résumé: En lisant des travaux récents dans le domaine, quelqu'un qui ne connaît pas la théorie de l'argumentation serait peut-être amusé de constater que nous, les spécialistes, ne suivons pas nos propres conseils. Nous avançons nos théories, mais nous ne discutons pas toujours les uns avec les autres-- c'est-à-dire que nous ne nous engageons pas dans de vrais arguments. $\mathrm{Si}$ nous cherchons à résoudre ce problème, les essais par William Rehg et Robert Asen représentent un bon début. Dans mon article je veux d'abord montrer comment Rehg et Asen reconnaissent bel et bien deux défis que nous devons tous relever et, ensuite, examiner les solutions de chacun à ces difficultés.
\end{abstract}

Keywords: William Rehg, Robert Asen, levels of argument, transactional argumentation

\section{Two challenges for contemporary argument theorists}

Interaction among argument theories can happen from the bottom up, as theorists with different views try to talk with each other about specific problems or issues. But it's also useful to proceed from top down, sketching a rough map of the terrain any theory can be expected to inhabit and examining it for disputed ground.

Wenzel's (1990) influential map encouraged us to distinguish "logic, dialectic and rhetoric" conceived as distinct perspectives, each responsible for investigating a particular aspect of argument, with a particular aim, and deploying a particular conceptualization. As Rehg points out, however, there is now so much slippage between these three enterprises that the distinction seems no longer useful (see also Jacobs, 2000). "Dialectics," at least in the form of pragma-dialectics, is colonizing "rhetoric;" it already absorbed "logic" among its commandments. "Rhetoric" since its revival in the early 20 th century has taught argument forms as its own informal "logic," and has developed "dialectical" views as well. 
Logicians, dialecticians and rhetoricians do differ from each other, and from those in political theory and post-Aristotelian enterprises like conversation analysis and artificial intelligence, but not in any neatly definable way. Nor is it obvious that their differences should make a difference. Theorists in all camps largely share a passionate (if sometimes obscure) sense that good argument is vital for democracy to flourish; many of us are also responsibie for teaching undergraduates to argue well. We therefore aim to develop theories that will ground the assessments of good and bad we and our students need to make; that is, we want to build normative theories of argument.

Following Rehg, it may be more useful to adopt a revised perspectivism which makes two independent sets of distinctions: first, a distinction between different "levels" or "components of argument-making practices" that are "descriptively available" to all theories; and second, a distinction between different "analyticevaluative perspectives" on argument that specify the normative orientation taken by the theory toward these components.

Consider first the distinction among "levels." Notoriously, the word "argument" has an accordion-like nature: "an argument" can be as small as a single sentence expressing a premise and conclusion or as large as a longstanding national controversy. Within this spectrum, though, it's possible and useful to tease out at least three relatively independent levels of activity.

At one level we have argument conceived as a sort of unit of discourse (traditionally, a "product"). "Argument" here refers to a "content" of a particular sort expressed (ordinarily) in language. "Reason" is a rough synonym. Studying argument at this level requires attention to the ways one proposition can give support to another, often by identifying different structures or schemes, as well as to the virtues that makes component good. Study of argument at this level seems to call for diagrams or other ways of making evident the relationships between propositions.

At another level we have argument conceived as a sort of transaction (to borrow a term from Edwin Black, 1965, ch. 5, to replace the traditional "procedure"). "Argument" here refers to something specific people are doing in a specific context. "Debate" is a rough synonym. Studying argument at this level requires attention to the ways the conversation is managed: how, for example, participants undertake and impose obligations to argue, how they take a stand, raise issues, make a case and at last close their discussion. Study of argument at this level seems to require a language of agency, identifying the goals participants have and the strategic actions they pursue to achieve them.

At yet another level we have argument conceived as-there is no set term for it, but "social" or "social-institutional" phenomenon (to adopt Rehg's term, replacing "process") seems to work. "Argument" here refers to something "decentered," occurring within or between social groups. "Controversy" is a rough synonym. Studying argument at this level requires attending to constitutional structures (in the widest sense): the institutions, publics, media and so on through 
which discourse flows, and which potentially limit or distort it. Such study seems to demand spatial metaphors, as talk of "spheres," "networks," open and closed "sites," "flows" and "movements" suggests.

The three levels are obviously linked. Arguments at the social-institutional level emerge out of a body of individual debates. These overarching controversies in turn provide environments in which specific transactions can flourish, for example by making available to participants commonplace arguments (topoi) they can deploy. Still, each level retains a relative integrity. As Rehg puts it, the public sphere is not a "macro-dialogue." It seems just as inadequate to import agency language at the socialinstitutional level (e.g., imagining an individual intervening to alter the "flow" of a social controversy) as it does to import spatial language at the transactional level (e.g., imagining a "discourse" speaking itself).

As Jeff Yoshimi (2004) has recently pointed out, we accept a similar distinction among "levels" within biology, recognizing a hierarchy stretching from organic molecules, through cells, through organisms, up to the ecologies that embrace them all. Arguments, analogously, can be decomposed into simpler parts and aggregated into more complex systems. Or consider another analogy: to the economy, an idea that in Charles Taylor's (1995) account emerged roughly simultaneously with that of the public sphere. I pay the check-out lady for my carrots; out of an indefinite number of transactions like this (appropriately interrelated), an economy emerges. I argue with the check-out lady about food stamp policy; out of an indefinite number of transactions like this (appropriately interrelated), public opinion emerges. Conversely, the particular transactions can only be accomplished because there's an economy or public sphere that circulates the resources necessary for it to take place, such as money, or commonplace arguments.

Distinguishing among these different "levels" helps us sort out some of the currents within contemporary argument theory. Let me tell a story from my own field's history as an example. The study of argument in Communication opened with a primary focus on argumentative transactions. The first article in the first issue of what would become the Quarterly Journal of Speech was devoted to the organization of public discussions and debates (Lyman, 1915), and the groundbreaking work proposing a science of Communication (Woolbert, 1917) was originally intended to clarify basic concepts in debate theory. By the late 1970s, however, the interest of Communication scholars had begun to shift from transactions to the social-institutional level. One sign of this shift was the interest in "argument fields" (e.g., Willard, 1982) or "spheres of argument" (Goodnight, 1982), both conceptions proposing a social basis for sound reasoning. Also important were the early movement studies, which later blossomed into studies of social controversy (Goodnight, 1991; and for specific examples the essays in the 1991 special issue of Argumentation and Advocacy). Social-institutional scholarship, and in particular public sphere theory, is now one of the most active areas within the Communication field, as well represented by Asen's own work as theorist 
$(1999,2000)$ and editor (Asen \& Brouwer, 2001).

Others could probably tell similar stories from their own fields; contemporary argument theory is, I believe, conspicuously flourishing, with strong work being done on argument as conceived at every level. And noticing the wealth of inquiry at every level, we are now in a position to ask both how the theories relate, and how they differ from each other.

First, recognizing the descriptive distinctions among levels challenges us to articulate more fully how theories centered on one level can be related to theories centered on another. There is a compelling intuition that argument goodness is continuous between levels: that sound units of argument make for and are made in constructive debates, that constructive debates contribute to and arise within healthy public spheres. At least as an aspiration, argument theorists should aim to try this intuition by attempting something like a "unified theory of argument," in which the norms appropriate to assessing argument at each level integrate with, extend, complement (etc.) the norms appropriate to the others. ' Even short of this aspiration, anything like a thorough assessment of a specific argument will require attention to all three levels, and we need some ways to coordinate the commentaries that various theories will produce.

Second, recognizing descriptive distinctions among levels challenges us to articulate more fully the ways that theories differ in the analytic-evaluative perspectives they adopt. To do this will require us to pay attention to the second set of distinctions proposed by Rehg's revised perspectivism. Every normative theory of argument proposes, or at least presupposes, a view of the dignity of argument. At the moment, differences among normative orientations are relatively invisible, swamped by all the many other ways that the theories diverge. But as some of the differences in descriptive approaches get sorted out (and as theorists learn to speak the languages of each other's fields) it seems certain that differences in evaluative perspectives will become more noticeable; and with notice will come the burden of adjudicating among them.

All of which is a long way of introducing the virtues of the essays by Rehg and Asen. Rehg with unique clarity constructs the scaffolding of a unified theory of argument, demonstrating how a single evaluative perspective can yield distinct, although interdependent, ways of assessing the merits of an argument considered as a unit, as a move in a transaction, and as a contribution to the public sphere. Asen then provides a challenge to this evaluative perspective, developing evidence that some of our best practices diverge from these norms. Let me proceed to fill out this terse summary.

\section{Toward a unified theory of argument as justifying collective judgments}

Rehg makes the case for acknowledging a family resemblance between the analyticevaluative perspectives of the pragma-dialectical and the Habermasian projects. Each, as he points out, works from a conception of argument as fundamentally "dialectical," 
viz. as aimed at making reasonable collective judgments, or at least at enhancing mutual understanding. Even better, the two projects have complementary strengths: where the pragma-dialecticians apply this perspective most successfully to the study and evaluation of argumentative transactions, Habermas applies it to the study and evaluation of argument at the social-institutional level. But, Rehg concludes, the two projects also have complementary weaknesses, which Rehg proposes to correct.

Before exploring Rehg's correction, I want to reconstruct in somewhat greater detail the analytic-evaluative perspective the two theories share. Anyone with a sense of shame would fear lecturing Rehg on Habermasian theory, so I will hide behind an over-simplification of his own (1994) work on the subject. Habermas (per Rehg) is looking for a way to justify the norms operative in both ethics and politics, in opposition to those who deny that justification is possible and those (e.g., communitarians or emotivists) who deny that there's a way to do it. He proceeds by articulating the deep presumptions upon which our practices of norm-setting inevitably rest. $\mathrm{He}$ reasons as follows:

(1) When we disagree about what to do, we ought to argue about it.

(2) When we argue, we presume that we are cooperating to resolve our disagreement by convincing each other using good reasons.

(3) In specific, we presume that we convince each other by showing that the action falls (or does not fall) under a norm.

(4a) Norms pick out courses of action which satisfy others' interests and thus which others will have reason to accept; and further,

(4b) We presume that these "others" with whom we argue include everyone, equally and freely.

(5) We must therefore acknowledge as justified norms which "rest on reasons all those subject to (and affected by) [them] can accept in open debate" (Rehg, 1994, 66); and therefore also acknowledge as legitimate laws which reflect or respond to such reasons.

Habermas thus shows how we can move in appropriate cases from observing a widespread and properly formed agreement about a norm to accepting its legitimate force, a general working principle that grounds a discourse ethics and a deliberative theory of politics—although admittedly the gap "Between Facts and Norms" now stretches across 631 pages.

Let me give the pragma-dialecticians even shorter shrift. As the basic working principles of their project, they endorse a conception of argument as oriented to the goal (functionalization) of enabling people who disagree (socialization) to resolve their dispute by convincing each other with good reasons (dialectification; van Eemeren \& Grootendorst, 1984, c. 1). In other words, they also endorse (2).

It is this agreement on (2) that gives both theories a "dialectical" or epistemic cast. What is (2)? It is not a description of what arguing may look like, as if observed 
from outside. Rather, it aims to capture what arguers ordinarily and inevitably presume, i.e., expect on normative grounds (see Kauffeld, 1998), when arguing. Arguers predict others' actions and regulate their own, relying on these presumptions; based on them, they praise or criticize. According to both Habermas and the pragma-dialecticians, arguers, including us, take argument to be "aimed at" what Rehg calls "fostering critically tested, generally convincing outcomes." Where Habermas adopts this basic conception and elaborates (4), the socialinstitutional arrangements under which people can be said to be equal, free and included, the pragma-dialecticians adopt it and elaborate at around the level of (3), articulating ten or so commandments as the transactional norms for achieving conviction. Together, the two projects (or projects along similar lines) thus plausibly constitute a unified "dialectical" theory of argument.

So the theories share a commitment to (2), and complement each other by elaborating this basic presumption on the transactional and social-institutional levels. What then are the theories' complementary weaknesses? Both of course confront the challenge facing all normative theories, that of bringing idealizations to bear the messiness of actual practice. But in specific, in Rehg's view the Habermasian project has trouble "scaling down" its social-institutional norms to the point where they might be realized in specific transactions, while the pragma-dialectical project has trouble "scaling up" its transactional norms to deal with the de-centered deliberations of the public sphere. A Habermasian will have difficulty specifying on principled grounds just how the debate over what memorial to construct on the $9 / 11$ site can be brought to a close and still count as "open," while a pragma-dialectician will struggle to justify which side has the burden of proof (and thus will likely lose) in the controversy over the safety of GMO foods (see Gaskins, 1995, for further examples).

In his essay, Rehg sketches an elegant solution to this problem, proposing what could (echoing the Tenth Federalist Paper) be called a "dialectical" remedy for the diseases most incident to "dialectical" theorizing. Rehg asks specifically how we ought to determine the cogency of an argument, i.e., its goodness in the most general sense. Following the general line of thinking mandated by discourse ethics, the starting point must be that an argument is cogent if it is accepted as cogent in the particular transactions and in the macro-level social controversies in which it takes place. But since transactions can be unruly and controversies distorted, this condition is not sufficient to establish cogency. We must go on to ask: when can (empirically observable) widespread agreement that an argument is cogent be taken as a sign that the argument is indeed (normatively) cogent? As above, one cannot simply say "when the transactional and/or social-institutional norms have been followed," because those norms are indeterminate. Instead, I read Rehg as proposing in part that to be cogent, an argument must not only be agreed, after argument, to be cogent in an argumentative transaction and/or social-institutional process; it also must be agreed, after argument, that the transaction and/or process itself realized the relevant idealizations, revealing it to be the sort of transaction and/or process in which cogent arguments will be recognized as such. 
Rehg here takes advantage of the reflexive or recursive nature of argument, and of talk generally. In arguing, we not only make and test arguments; we also can and do argue about the conditions under which we are doing so. It is common, for example, for an arguer not only to give reasons against another's reasons, but also to object with reason to the assignment of a burden of proof, or to complain with reason of being silenced or disadvantaged.

Rehg's discussion makes it relatively clear how this sort of meta-arguing is supposed to work at the social-institutional level. It is plausible that an argument is a good one when it (however we are to identify "it") survives scrutiny in a wide variety of argumentative transactions. But how wide is "wide"? As Asen's essay documents, there are well-developed lines of scholarship objecting to specific social-institutional arrangements for linking up or "networking" transactions (e.g., the bourgeois public sphere) as insufficiently open, equal and free; and moreover objecting even to Habermas' general conception of what adequate social-institutional arrangements might look like (e.g., a unified public sphere). What is noncontroversially taken as a "good argument" within such questionable arrangements therefore may not be cogent. Now, many in these disputes (based on my far from comprehensive reading) call upon the same, abstract idealizations, which cannot on their own resolve the disagreement. But in making their charges and responses, they inevitably go beyond the idealizations to claim specific ways in which existing or hypothetical institutions pass or fail to pass muster. They employ the idealizations as topoi-commonplace re-sources of argument, that they make determinate in the context of their specific controversy. As Rehg puts it:

The critique of a discussion as exclusive, unequal, or coercive has force only if the invocation of the corresponding ideals (inclusion, equal voice, non-coercion) is accompanied by substantive arguments, for example, arguments showing that certain institutional or social constraints and pressures undermine goals of the argumentative enterprise specific to that domain. (Supra, p. 108.)

And once such substantive arguments are put forward, they can be tested through further argument. The outcome of this intensely "local" activity will (hopefully) be an agreement about the adequacy of a particular social-institutional arrangement as supporting or not supporting sound cogency assessments of arguments within a given controversy, an agreement which will in turn validate or invalidate the arguments taken as cogent within it.

Aside from the danger of an endless recursion-in which the adequacy of the meta-argument is itself called into question, leading to a meta-meta-argument and so on-aside from this problem, Rehg's proposal seems quite attractive. Indeed, it appears to me to run in parallel with Benhabib's similar, though more abstract, idea that in good deliberations, "all have the right to initiate reflexive arguments about the very rules of the discourse procedure and the way in which they are applied or carried out" $(1996,70)$.

Rehg proposes a similar "localization" for the assessment of the transactional merits of an argument. Rules such as those proposed by the pragma-dialecticians 
"receive their full sense for an argumentative interaction only when the participants in the interaction appropriately contextualize the rules . . . in their local context." Since such contextualization is likely to be sometimes controversial, I presume that Rehg would endorse the idea that judgments of the "appropriateness" of a specific contextualization are defended with arguments. For example, transactional norms (e.g., assigning a burden of proof) can in fact be invoked in the course of a transaction to challenge specific moves; the resulting meta-argument could, if resolved, validate the transaction and thus the arguments taken as cogent within it.

As I read it, however, Rehg is saying something in addition, and stronger. Not only are transactional norms of the sort specified by pragma-dialectical (or similar) theory made determinate (specific, particular) and valid through meta-argument within particular transactions; it is also the case that the arguers in a transaction work creatively, designing the conditions under which their arguments can be judged cogent (see also Goodwin, 2004).

What does this mean? Rehg's repeated references to ethnomethodology (in this essay and in Rehg, 2005) may give us a clue. The ethnomethodological approach encourages us not to consider participants as following pre-given scripts or rules, but instead to examine how social order arises out of and is maintained in and through the interaction itself. Applied to the transaction of arguing, this approach suggests we take the norms operative in a transaction as something the arguers themselves craft. If they expect certain norms to be in force, it is because they have made them so. This is not a new idea. In particular, it has been fruitful to conceive of all the other talk that goes on in an argument, over and above the arguments, as helping perform this norm-creating task. Rehg's own work (1997) has suggested how appeals to ethos and pathos can create the conditions in which good judgment can be exercised. Scott Jacobs has put forward a similar idea, showing how stylistic and visual elements serve to address hindrances to judgment (1999; see also his contribution in van Eemeren et al., 1993, c. 6). And Fred Kauffeld and I have shown how the speech acts surrounding arguments can accomplish important tasks such as assigning the burden of proof and making available adequate premises (Kauffeld, 1998, 2002; Goodwin, 2002, 2005).

If this is what Rehg means, then he is both admirable and in debt. Admirable, in calling for serious attention to the local, situated, context-specific norms that arguers design to regulate their transactions. In debt, since the ethnographic work this approach requires is at best just begun.

In addition to admirable and in debt, I think Rehg is also potentially in trouble. The ethnographic work he calls for aims to articulate the often only implicit presumptions arguers rely on when they argue. It may turn out that when articulated, these local presumptions will everywhere be discovered to be specifications or determinations of (2). In other words, all arguers everywhere may be working to realize locally the social-institutional and transactional conditions for reasonable judgment. But it may turn out otherwise. Perhaps somewhere arguers' design 
work runs deeper. They may not think that rational dispute resolution is really what their transaction is about. They may proceed not to fill in a pre-given foundational presumption, but to lay their own foundations. So Rehg's ethnomethodological turn commits him to asking: Is (2) in actuality an adequate articulation of the foundational presumptions of all argumentative practice? Is a "dialectical" analytic-evaluative perspective—one that sees argument as aimed at collective reasonableness-defensible?

We already have reason to be suspicious of (2). Although Habermas, or Rehg, gives a defense to (1), (3), (4) and (5), I have not yet found in the Habermasian corpus a defense of (2). Instead, I have found citations to the long or short versions of Alexy $(1989,1990)$. But although Alexy does offer an account of how one might go about defending a set of transactional norms, he does not go very far in actually doing so. This arouses the speculation that Habermas' statement of the fundamental presumptions of argument is a sort of elaborate way of assuming the conclusion. Habermas is looking for a way to find norms that everyone has reason to acknowledge (i.e., (5)); is it a surprise that arguing (in his view) then turns out to be a process in which through the exchange of reasons everyone ends up acknowledging a norm (i.e., (2))? At least the pragma-dialecticians are more up front with their axioms. Their project is framed as hypothetical: if we take arguing to be aimed at the rational resolution of disputes, then this is the way we should act. Of course, academic freedom allows any theorist to adopt any analytic-evaluative perspective on argument hypothetically. But I take it that Rehg's expressed commitment to untangling actual argumentative transactions prevents him from taking this line. ${ }^{2}$

Indeed, we already have some reason to deny (2); this is what Asen's essay gives us. To it I now turn.

\section{Alternative normative perspectives on argument}

The burden of Asen's paper is to establish that argumentative transactions cannot be conceived exclusively as aimed at what he calls "external justification." I want to suggest that what Asen identifies as the external-justificatory conception overlaps with what Rehg is calling the "dialectical" analytic-evaluative perspective. Thus Asen's general critique of external-justificationism bears also against Rehg's proposal, and Asen's three documented alternatives (agenda expansion, responsibility attribution, and identity formation) begin to demonstrate what else argument could be taken as doing.

Asen's first move is to distinguish a core or "internal" sense of justification, according to which "the premises of an argument justify - or provide support for-its conclusions." Although Asen himself is more cautious, I would be happy to admit that we identify a stretch of interaction as an argument because a justification of a conclusion is expressed (ostended, shown, made evident) within it-Asen's "internal justification" or Blair's justification sense \#1 (p. 145). Indeed, something like this, or the equally minimal and descriptive conception proposed by Jacobs 
(2000), may be necessary to identify a common ground for normative theorists to dispute over.

By contrast, to conceive argument as justifying in what Asen calls the "external" sense (Blair's sense \#3, p.146). is to go beyond description and adopt an analyticevaluative perspective, one focusing on the function of argument in rational persuasion. Asen traces the way this perspective has been articulated, apparently independently, by argument theorists such as Stephen Toulmin and political theorists such as Joshua Cohen. For these authors, to take argument as externally justifying is to

ascribe particular competencies, expectations, roles, and aims to advocates and audiences. From this perspective, people typically undertake argument in a situation in which a problem has arisen and a decision needs to be reached. ... The role of argument appears to be the restoration of an equilibrium that has been disrupted by the emergence of a problem. Restoration occurs by reaching a decision. ... Justification, then, tends to associate argument with situations of problem-solving, decision-making, and conflict resolution. (Supra, p. 123)

The similarities of external justification and the "dialectical" presuppositions expressed in (2) above should be obvious. Both external justification and "dialectics" stress resolution and reason. It is true that (2) invokes an additional requirement of cooperation, but I expect Asen would accept this as another feature of justification. Certainly the illustrations he suggests - arguments at a school board, interpersonal arguments over religion in the White House-have cooperative overtones: they portray arguers working together to find a solution to their common problem.

So I want to propose an equation: Rehg's presumptions which a "dialectical" analytic-evaluative approach assumes to be operative in argumentative transactions = (2) = the justificatory function of arguments, in Asen's "external" account.

What then does Asen take to be wrong with an external-justificatory conception of argument? For one thing, it dissolves away the idiosyncrasies of actual transactions. Asen explicitly allows that the norms governing argumentative transactions are local. Further, these local norms in Asen's view arise at least in part from the activities of the arguers themselves. For example, the premises of arguments "need to be negotiated through debate." He similarly notes that in arguing, arguers can "reshape the social context within which deliberation normally occurs." So if nothing else, the fact that local transactional norms are a product of the arguers' own activities renders it unlikely that all arguers in all situations will end up orienting towards the same set of norms.

Moreover, Asen contends, contemporary public sphere theory has developed thick conceptions at the social-institutional level that directly impact transactional arguments. As Asen puts it:

First, all discursive forums reflect the histories of their participants. This means that no discursive forum proceeds as a tabula rasa but comes heavily coded with participatory norms. . . . Susceptible to change, [these] norms provide a structuring influence on interactions. As reflective of specific 
histories, these norms advantage some participants and disadvantage others. Calls for "dispassionate" debate, for example, may actually reflect culturally specific ways of interacting. ... Second, participants speak from different positions in social hierarchies and networks, and these different positions have a bearing on the reception of one's discourse. ... In . . our contemporary society, ... status bracketing is impossible. Put differently, the force of the better argument does not wholly decide how people deliberate about public matters. (Supra, pp. 125-126)

The norms local to a particular transaction are informed by the unique histories and roles participants bring to it; we cannot therefore expect argument to be everywhere governed by the same set of norms.

Asen fills out these general remarks about the variability of transactional norms with brief case studies of three significant contributions argumentative transactions can make to the public sphere, each of which goes beyond rational persuasion in important respects. The challenge Specialist Wilson made to U.S. Defense Secretary Rumsfeld opened the "botched planning" of the invasion of Iraq as an issue in the public sphere. Opponents of fated changes in welfare policy presented arguments in late-night hearings in order to establish a record that would force those in power to accept responsibility for the consequences of their decisions. And a resident of South Central Los Angeles helped form the identity of his community by defending it with arguments.

In his commentary on Asen, J.Anthony Blair raises an important objection to Asen's account of these three functions of argument. In each case, Blair suggests, the real or at least apparent function of the argument was rational persuasion. Specialist Wilson, the welfare advocates and the citizen of South Central were in this view all ostensibly attempting to persuade. To the extent they were all also achieving, and perhaps even aiming to achieve, other consequences, those consequences were derivative from the central function of rational persuasion. This is because, Blair suggests, something like rational persuasion is indeed the ineliminable, central function of argument in the public sphere; if rational persuasion is impossible, there are no public spheres.

Rehg, I take it, would likely agree with Blair's objection, and possibly even extend it further. As I sketched above, Rehg proposes a mechanism whereby the abstract pragma-dialectical and Habermasian norms are made determinate in particular contexts through the activities of the participants. He recognizes that arguments (as well as other devices, such as appeals to ethos and pathos) perform important functions in reconstructing situations to create an environment in which reasonable judgments are formed. Applying this insight to Asen's case studies, Rehg could note that agenda setting, responsibility attribution and identity formation are indeed important preconditions for reasonable decision-making. From the "dialectical" perspective, participants ought to direct their attention to the real issues, accept responsibility for their positions and acknowledge each other's worth. If in a particular context histories or inequalities mean that the agenda is manipulated, participants free to wriggle out of their commitments, and some potential participants dismissed as 
incompetent, then we will certainly need strategies-including arguments-to reconstruct the context, and bring it into line with the "dialectical" norms.

The question, however, is not whether Asen's alternative functions can serve dialectical goals, but whether they must. Is it possible to offer an argument without purporting to rationally persuade, to seek a reasonable resolution of a disagreement, or to perform any other function of argument within the "dialectical" family of views? The answer to this appears to be "yes." In each of Asen's three cases, the speaker could have prefaced his argument by saying "I don't expect to persuade you with reasons-indeed, I'm not even going to try-still...", and this caveat would not have affected the force of what he said.

Furthermore, such "non-persuasive" arguments can have consequences beyond fostering the conditions for reasonable decision-making. These consequences arise not because arguments provide Asen's external justifications, but because they offer his internal ones. An arguer by his argument makes it manifest that a conclusion is justified by reasons. What can thereby be accomplished?

At times, this showing can make an issue of something previously taken for granted, inducing, or even obliging, others to make it equally manifest that their opposing views are also justified. Such crafting of issues or agenda setting may be an early step in a longer, resolution-oriented deliberative process. But it need not be. The arguer may think that his opponent's views are in fact unjustifiable, and that his opponent's "rambling" response to the issue will make that fact manifest to all. Whether or not the inadequate response changes anyone's views on the issue, in such a case publicity has been strategically crafted to force an alteration in social relations: in how people stand in respect to each other, and in the treatment they can legitimately expect and accord. Argument has created a new public fact: a person has conspicuously failed to address an issue.

At times, an arguer raises an issue intending for it to be answered. In such cases, the arguer wants his showing of internal justification to provoke a corresponding showing of internal justification from the other side. Likely, the arguer will expect his opponent's showing to be inadequate. But he need not expect the broader public to recognize this immediately. Instead, he may hold the bittersweet hope that the disastrous consequences of his opponent's views will eventually teach the public a lesson. Meanwhile, by forcing his opponent to lay out his commitments in advance of the disaster, the arguer makes it more difficult for his opponent to evade eventual responsibility by, say, claiming that he "could not have foreseen" it. The arguer is thus creating the conditions under which a decision-maker can be held responsible for his decision; again, publicity has been crafted strategically to force an alteration of social relations.

At times, and perhaps most basically, an arguer ostends an argument to make evident something about himself: namely, that he is a person capable of justifying his views (internal justification in Blair's sense \#2). This showing can be the basis for claiming respect from others, an important precondition for arguments which 
aim to resolve disagreements - but for, again, all sorts of other social relations as well.

In these three sketches, I have been trying to add an additional line of defense to Asen's basic contention that there are norms of argument beyond those of external justification. In each case, I have tried to articulate what argument could plausibly contribute to a public sphere simply by making reason, public. Getting others to see reason can be consequential in ways that are not derivative from the function making reasonable decisions, or even attaining mutual understanding; there are non-epistemic functions that reason-giving can perform.

To fill out these sketches or indeed Asen's main proposal requires more ethnographic or similar case work; further, I suspect that even thicker accounts need to be given of how the forces of argument arise. Asen's discussion of the function of arguments in agenda setting, holding responsible and establishing identity, together with his general critique, are however enough to raise a serious possibility that "dialectical"/external justificatory presumptions are not the only ones available to arguers in practice, and thus that a unified "dialectical" theory of argument, such as Rehg's, covers at best only a portion of the terrain.

\section{Summary}

If argument theorists are going to start talking with each other, we will first need to emulate the care Rehg and Asen have exercised in accomplishing two of the central tasks facing us.

Rehg constructs the scaffolding for a unified theory that justifies distinct, yet interdependent assessments of the merits of argument on three descriptive levels: argument as unit, as transaction and as social-institutional phenomenon. In doing so, he articulates his "dialectical' normative orientation with precision enough to render it capable of defense, and of challenge. Asen provides that challenge, mustering contemporary public sphere theory and contemporary examples to call on us to acknowledge the diversity of legitimate functions argument can achieve in addition to the often-assumed one of externally justifying a claim to an audience.

It's worth noting that both Rehg and Asen endorse the "locality" of transactional norms. Indeed, both may endorse a stronger claim: that arguers themselves are responsible for crafting at least some of the norms regulating their activity. This induces both to insist on the "networked" complexity of the public spheres that emerge from and provide an environment for these ineluctably local argumentative transactions. And it suggests that I'm licensed to issue the commonplace end-ofcommentary call with special insistence. If the norms of argument hug the ground of actual practice so closely, then argument theorists must answer a third challenge. In addition to constructing theory that covers multiple descriptive levels of argument, and that specifies and defends a normative perspective, we must continue to stay honest by paying close attention to the particulars of best practice. Much 
more work is needed.

\section{Notes}

'If the levels are, as I have proposed, relatively independent, then the easiest solution-reductionist or imperialist attempts to declare one level more fundamental than the others-should be resisted on principle.

${ }^{2}$ As I believe does Habermas" "transcendental" deduction strategy, which must start from the pragmatic presuppositions of the activity of arguing we already find ourselves engaged in.

\section{References}

Alexy, R. (1990). A theory of practical discourse. In S. Benhabib and F. Dallmayr (Eds.), The communicative ethics controversy (pp. 151-90). Cambridge, MA: MIT Press.

Alexy, R. (1989). A theory of legal argumentation: The theory of rational discourse as theory of legaljustification. Oxford: Oxford University Press.

Asen, R. (1999). Toward a normative conception of difference in public deliberation. Argumentation \& Advocacy, 35, 115-129.

Asen, R. (2000). Seeking the "counter" in counterpublics. Communication Theory, 10, 424446.

Asen, R. \& Brouwer, D.C. (Eds.). (2001) Counterpublics and the state. Albany, NY: SUNY Press.

Benhabib, S. (1996). Toward a deliberative model of democratic legitimacy. In S. Benhabib (Ed.), Democracy and Difference: Contesting the Boundaries of the Political (pp. 6794). Princeton, NJ: Princeton UP.

Black, E. (1965). Rhetorical criticism: A study in method. New York, NY: The Macmillan Company.

Eemeren, F.H. van, and R. Grootendorst. (1984). Speech acts in argumentative discussions. Dordrecht: Foris Publications.

Eemeren, F.H. van, R. Grootendorst, S. Jackson, and S. Jacobs. (1993). Reconstructing argumentative discourse. Tuscaloosa, AL: University of Alabama.Press.

Gaskins, R.H. (1995). Burdens of proof in modern discourse. New Haven, CN: Yale University Press

Goodnight, G.T. (1991). Controversy. In D.W. Parson (Ed.), Argument in Controversy: Proceedings of the 7th SCA/AFA Summer Conference on Argumentation (pp. 1-13). Annandale, VA: SCA.

Goodnight, G.T. (1982). The personal, technical, and public spheres of argument: A speculative inquiry into the art of public deliberation. Journal of the American Forensic Association, $18,214-227$.

Goodwin, J. (2005). Designing premises. In F.H. van Eemeren and P. Houtlosser (Eds.), Argumentation in Practice (pp. 99-114). Amsterdam: John Benjamins.

Goodwin, J. (2004). One question, two answers. In H.V. Hansen et al. (Eds.), Argumentation and its Applications, Proceedings of the Ontario Society for the Study of Argumentation Conference, 2001. (CD-ROM). 
Goodwin, J. (2002). Designing issues. In F.H. van Eemeren et al. (Eds.), Dialectic and Rhetoric: The Warp and Woof of Argumentation Analysis (pp. 81-96). Amsterdam: Kluwer

Jacobs, S. (2000). Rhetoric and dialectic from the standpoint of normative pragmatics. Argumentation, 14, 261-286.

Jacobs, S. (1999). Argumentation as normative pragmatics. In F.H. van Eemeren et al. (Eds.), Proceedings of the fourth international conference of the International Society for the Study of Argumentation (pp. 397-403). Amsterdam: Sic Sat.

Kauffeld, F. J. (2002). Pivotal issues and norms in rhetorical theories of argumentation. In F.H. van Eemeren and P. Houtlosser (Eds.), Dialectic and rhetoric: The warp and woof of argumentation analysis (pp. 97-118). Dordrecht: Kluwer Academic Publishers.

Kauffeld, F.J. (1998). Presumptions and the distribution of argumentative burdens in acts of proposing and accusing, Argumentation, 12, 245-66.

Lyman, R.L. (1915). The forum as an educative agency. Quarterly Journal of Public Speaking, $1,1-8$.

Rehg, W. (2005). Ideals of argumentative process and the ethnomethodology of scientific work: Implications for critical social theory. Symposium, 9, 313-337.

Rehg, W. (1997). Reason and rhetoric in Habermas's theory of argumentation. In W. Jost and M.J. Hyde (Eds.), Rhetoric and hermeneutics in our time, (pp. 358-377). New Haven, $\mathrm{CN}$ : Yale University Press

Rehg, W. (1994). Insight and solidarity: The discourse ethics of Jürgen Habermas. Berkeley, CA: University of California Press.

Taylor, C. (1995). Invoking civil society. In Philosophical Arguments (pp. 204-24). Cambridge, MA: Harvard University Press.

Wenzel, J. (1990). Three perspectives on argument. In R. Trapp and J. Schuetz (Eds.), Perspectives on argumentation: Essays in honor of Wayne Brockriede (pp. 9-26). Prospect Heights, IL.: Waveland Press.

Willard, C.A. (1982). Argument fields. In J.R. Cox \& C.A. Willard (Eds.), Advances in argumentation theory and research (pp. 24-77). Carbondale, IL: SIU Press.

Woolbert, C. H. (1917). Conviction and persuasion: Some considerations of theory. Quarterly Journal of Public Speaking, 3, 250-64.

Yoshimi, J. (2004). Mapping the structure of debate. Informal Logic, 24, 1-21.

Jean Goodwin Department of English

223 Ross Hall

Iowa State University

Ames, Iowa

$50011-1201$

goodwin@iastate.edu 